\title{
Breast cancer research neglects non-Jewish groups, experts charge
}

Soon after scientists in 1994 identified the first genes linked to breast cancer, they discovered mutations among Ashkenazi Jews. But did this early success skew research into breast cancer?

The focus on the Ashkenazi has distracted scientists from finding mutations in other ๖ groups, some experts say. They suggest that scientists should concentrate on geographical ancestry rather than on ethnicity.

Aided in part by the relative ease of assembling Jewish study cohorts and DNA databases established for fighting Tay-Sachs disease, researchers identified three mutations in BRCA1 and BRCA2, which together account for $95 \%$ of $B R C A$-linked breast cancers in Ashkenazi women. Ashkenazi Jews are of Central and Eastern European descent and comprise about $90 \%$ of American Jews.

The three $B R C A$ mutations account for only a fraction of Ashkenazi breast cancers, but they are the strongest results yet found in a single group. With tests to focus on the three mutations, screening in Jewish women has become inexpensive and widespread.

Although the mutations are more frequent among the Ashkenazi, they are not unique to that population. One of the mutations has been found in large numbers in Jewish women of, among others, Greek, Iranian and Moroccan descent, along with non-Jewish South Indian, Spanish Gypsy and Hispanic women. Another of the mutations is widely found in non-Jewish people from Central and Eastern Europe and Greece.

"[Ashkenazi] women are more closely monitored," says Sheila Rothman, deputy director of Columbia University's Center for the Study of Society and Medicine. "But other women who may be at the same risk don't appear to have access to predictive testing."

Other common mutations have also been found worldwide. But little of that research is conducted by US scientists, who tend to use categories such as 'white' and 'AfricanAmerican' that are too broad to be meaningful.

Utah-based Myriad Genetics has also patented the BRCA genes and sells an Ashkenazi-specific test but offers no other ethnically tailored scans.

"Why don't they do Polish panels in the US? Because Myriad's interest is the full test," says Canadian researcher Steven Narod, who helped identify BRCA1 and offers tests tailored to Polish, Dutch and French-Canadian women.

The monopoly also squeezes academics.

Even at a discounted rate negotiated by the US National Institutes of Health, the BRCA screen costs $\$ 1,450$.

"Is that fair? Of course not," says MaryClaire King, whose work paved the way for the $B R C A$ identifications. "[But] it's controlled by one company, and they set prices."

Myriad's claims are more limited in Europe (Nat. Med. 10, 882; 2004), allowing other screens to emerge. But in the US, given the nonAshkenazi targets, King says, "the most clear and useful piece of information is whether a family has Ashkenazi Jewish ancestry."

Brandon Keim, New York

\section{US marijuana laws clamping the lid on pot research}

A decade after California became the first US state to legalize medical marijuana, one small survey estimates that doctors have recommended the drug to about 350,000 patients. But continuous legal wrangling with the federal government has scared researchers away from tapping into this vast pool to understand how the drug works.

"No one wants to do a bunch of research if medical marijuana is just going to disappear," says Rosalie Liccardo Pacula, co-director of the Drug Policy Research Center at the nonprofit RAND Corporation. As a result, she says, the past decade has been "a huge uncontrolled public health experiment."

The California law took effect in November 1996 without an accompanying patient registry or any monitoring scheme. The law grants immunity from state laws to individuals in California who have a recommendation from a physician. But in 2005, the US Supreme Court ruled that those individuals are not protected from federal prosecution.

In October, the federal Drug Enforcement Agency arrested 15 medical marijuana providers and users at eight California cannabis dispensaries, which are legal under the state law.

However, according to the new survey, published in November in O'Shaughnessy's, self-described as "a medical journal/political tabloid," some California doctors are convinced that marijuana has medical value. The 18

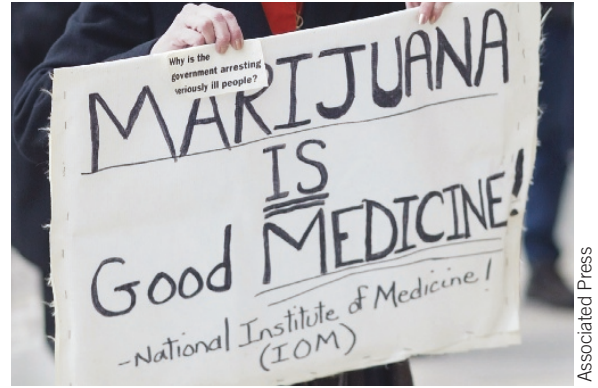

Weeded out: The US government arrests medical marijuana users.

physicians and one network of clinics surveyed had provided recommendations to 140,000 individuals during the past decade, a figure extrapolated to the state. About $95 \%$ of them had used marijuana medically before seeking a doctor's approval.

One surveyed specialist, Redding-based Philip Denney who is president of the Society of Cannabis Clinicians, identified the 'typical patient' as a male in his mid-40s with chronic low back pain. Among Denney's 18,900 recommendations for medical marijuana, roughly $50 \%$ were for chronic pain, $15 \%$ for gastrointestinal disorders, $15 \%$ for psychiatric disorders and $10 \%$ for neurological disorders such as multiple sclerosis. "What makes cannabis so attractive as a medicine is its safety," Denney says. "There's no such thing as an overdose."
In the survey, respondents consistently reported that cannabis helped reduce their reliance on opiates. "A typical story I hear is from the patient who was taking 260 milligrams of oxycontin a day and now with cannabis is down to 10 milligrams," Denney says.

California in 2002 also funded the Center for Medicinal Cannabis Research, housed at the University of California, San Diego. Among the fourteen clinical trials completed or underway: a placebo-controlled double-blind study of cannabis for neuropathic pain in individuals with HIV/AIDS, a study of cannabis versus the tranquilizer lorazepam for neuropathic pain, and a study of how well cannabis controls spasticity in multiple sclerosis. Researchers funded by the center are also studying how cannabis affects the immune system in those with HIV/AIDS.

"The state of California took a real chance on this," says Igor Grant, director of the center. "We're on our way to getting some answers."

Preliminary results in 50 individuals with HIV/AIDS show, for instance, that cannabis reduces neuropathic pain better than a placebo. As results from small trials trickle in, some observers lament the lost opportunity to conduct large-scale studies. Says Robert MacCoun, a law professor who studies drug policy at the University of California-Berkeley, "It's one consequence of this crazy system we have."

Brian Vastag, Washington DC 